\title{
The participation process of PEAK program for collegiate Taekwondo athletes: A grounded theory approach
}

\author{
Taehee Lim ${ }^{1}$, Oh-Jung Kwon ${ }^{2 *}$, Mi-Seon Yun ${ }^{1}$ Junsu Bae ${ }^{1}$, \& Yun-Kyung Yang ${ }^{3}$ \\ ${ }^{1}$ Yongin University, ${ }^{2}$ Konkuk University Continuing Education Center, \& ${ }^{3}$ Gangnam University
}

\begin{abstract}
[Purpose] The purpose of this study was to explore the process of participation in the PEAK program of collegiate athletes based on grounded theory. [Method] In-depth interviews were conducted with 12 athletes from Y University who were registered in Korea Taekwondo Association. The collected data were analyzed by using the open coding, axis coding, and selective coding of the grounded theory, completed the paradigm model among the extracted concepts, and extracted the core categories through the story outline. [Result] As the result of data analysis, 'participating in the PEAK program' was found as the central phenomenon, and the causal situation was 'bad attitude in class' and 'helpless daily life'. The contextual conditions were 'recognition of the need for class participation and dual career' and 'motivation to participate in the program', and the intervening conditions were 'factors that hinder participation in the program' and 'factors that help program participation'. The action/interaction strategies were 'caring climate' and 'promoting transfer', and depending on the consequence, 'learning attitude change' and 'life skill change' appeared. [Conclusion] Participants improved their learning attitude through the PEAK program and confirmed the possibility of life skills transfer. It is hoped that this study can lead to implementation of various studies and discussions about life skills and transfer.
\end{abstract}

Key words: life skills, learning attitude, positive development, explicit approach

\begin{abstract}
서 론
체육계의 고질적 문제들이 드러나면서 스포츠 환경의 혁 신이 필요하다는 목소리가 높다. 특히 학생선수들의 인권· 학습권·처우 문제는 운동을 통해 '무엇'을 배우고, '어떻게' 일상에 확장할 것인가에 대해 간과했음을 방증한다. 체육계 에서는 암묵적으로 이러한 내용의 중요성에 대해 언급해 왔
\end{abstract}

논문 투고일 : 2020. 12. 15.

논문 수정일 : 2021. 02. 26.

게재 확정일 : 2021. 03. 09.

* 교신저자 : 권오정(tkdhwjd@knsu.ac.kr)

* 이 논문은 2019년 대한민국 교육부와 한국연구재단의 지원을 받아 수행된 연구임 (NRF-2018S1A5A2A01038953)
으나 이론적 토대가 부족했다. 하지만 북미에서 파생된 긍 정심리학(positive psychology)과 긍정적 유소년 발달 (positive youth development, 이하 PYD) 그리고 스포 츠 기반 유소년 발달(sport based youth development, 이하 SBYD) 이론은 학생선수들이 스포츠 환경에서 라이프 스킬을 습득하고 개발하는 것을 우선시한다(Danish, Forneris, \& Wallace, 2005). 학생선수들은 운동을 통해 습득하는 긍정적 자원의 개발과 전이에 집중함으로써 스포 츠와 삶 사이에 균형 잡힌 자기계발이 가능하다.

라이프스킬(life skills)은 인간이 삶 속에서 겪는 역경에 효과적으로 대처하고 성공적인 삶을 살아가는 데 바탕이 되 는 사회·심리· 신체기술이다(Lim, 2019). 요컨대 목표설정, 
의사소통, 감정조절, 대인관계, 갈등해결, 스트레스 대처 등 이 좋은 예다(Gould \& Carson, 2008). 라이프스킬은 체계 적인 스포츠 및 신체활동을 통해 체득됨으로써 그 가치가 삶 으로 전이된다. 전이를 위해서는 의도적인 연습을 통해 학 습한 라이프스킬의 실천력을 높이는 것이 중요하다(Gould \& Carson, 2008; Lee, 2016; Lim, Yang, Bae, \& Yun, 2019). 이 때문에 인생의 축소판이라고 불리는 스포츠 환경 에서 라이프스킬을 체험할 때 교육 효과가 가장 크다 (Gould \& Carson, 2008; Pierce, Gould, Camiré, 2017). 스포츠가 라이프스킬을 함양할 수 있는 수단으로 밝혀지 면서 다양한 프로그램이 개발-적용되었다. 국외에서는 목표 추구 프로그램인 GOAL(Going for the goal; Danish, Meyer, Mash, Howard, Curl, \& Brunelle, 1998)과 SUPER(Sport United to Promote Education and Recreation; Danish, 2002), 골프기술과 9가지 핵심 가치 및 라이프스킬을 함께 배우는 The First Tee(Weiss, 2006), 미식축구 선수를 대상으로 한 Play It Smart(Petitpas, Raalte, Cornelius, \& Presbrey, 2004), 학생선수를 대상 으로 하는 DC(Developing Champion, Hardcastle, Tye, Glassey, Hagger, 2015) 프로그램, 그리고 유소년 아이스 하키 프로그램인 HIFE (Hockey Is For Everyone; NHL, 2020)와 라이프스킬 프로그램 SUPER를 합친 HIFE-SUPER (Hodge, Kanters, Forneris, Bocarro, \& Sayre- McCord, 2017) 등이 개발되었다.

최근 국내에서도 스포츠나 신체활동을 도구로 하여 참여 자들의 라이프스킬이나 강점 찾기, 역량을 개발하려는 시도 가 있었다. 라이프스킬의 개념을 소개한 탐색적 연구(Bae, Lim, \& Jang, 2019; Kwon, 2017; Lee, 2016; Lim \& Jang, 2017)를 시작으로 스포츠 라이프스킬 관련 검사지 개발(Jang, Lim, Bae, Jung, \& Kim, 2020; Lim, Bae, \& Jang, 2018; Lim, Kwon, Yang, Yun, \& Bae, 2019)이나 국외 라이프스킬 프로그램 적용 연구(Kwon, Lim, \& O'Sullivan, 2020; Lim \& Jang, 2017) 등이 대표적이다. 이들 선행연구에서는 공통적으로 국내 스포츠 환경에 맞는 라이프스킬 프로그램 개발과 적용 필요성을 제언하였다.

$\operatorname{Lim}(2019)$ 은 국외 라이프스킬 프로그램의 개념을 토대 로 PEAK 프로그램을 개발하였다. PEAK는 PerformanceEnhancement·Achievement Knowledge의 앞 글자를 딴 것으로, 스포츠를 통해 최고의 수행·향상·성취·지식을 습득한다는 의미를 내포하고 있다. PEAK 프로그램은 만나
기와 인사하기, 자기 이해하기, 꿈 찾기, 목표 설정하기, 긍 정적 생각하기, 마음 다지기, 유능감 높이기, 생활 관리하 기, 다름 인정하기, 소통능력 키우기, 관계 맺기, 갈등 해결 하기, 도움 주고받기 등의 주제로 이루어져 있다. $\operatorname{Lim}(2019)$ 은 국내 학생선수에게 PEAK 프로그램을 적용 하여 라이프스킬과 학습 태도의 향상을 검증하였다. 그리고 후속연구(Lim et al., 2019)를 통해 PEAK 프로그램이 대 학 선수의 라이프스킬과 회복탄력성 증진에 효과가 있음을 확인하였다. 이후 프로그램의 효과적인 활용을 위해 워크시 트를 개발하는 등, 프로그램의 타당성 확보를 위한 다양한 접근이 진행되고 있다.

PEAK 프로그램 관련 후속연구를 고찰하면서 여러 제한 점도 발견되었다. 효과성 검증을 위한 선행연구에서 참여자 들의 구체적인 체험 탐색을 위한 질적 접근이 부족하였다. PEAK 프로그램은 각 주제에 대한 이해·해보기·토론·반영 (반성)-평가 등으로 구성되었기 때문에 프로그램 참여자 중 심의 주관적 체험 과정에 초점을 둘 필요가 있다.

Holt 등(2017)은 메타분석을 통해 스포츠 라이프스 킬 프로그램의 과정과 결과 및 효과를 확인하였다. 이들 은 프로그램의 효과를 객관적으로 검증하는 것뿐만 아 니라 질적 연구의 중요성과 필요성을 강조하였다. 나아 가 Williams, Neil, Cropley, Woodman, 그리고 Roberts(2020) 또한 메타분석을 통해 라이프스킬 연구 의 활성화와 프로그램의 질적 개선을 위해서는 질적 연 구에 집중해야 함을 강조하였다. 이에 영향을 받은 Pierce, Erickson과 Dinu(2019)는 교사와 코치의 관 점에서 스포츠 라이프스킬이 교실로 전이되는 과정을 탐색하였다. Kendellen과 Camiré (2019)는 시간의 흐름에 따라 나타나는 라이프스킬의 전이과정을 탐색하 기 위해 종단적 접근에 기반한 질적 연구를 수행하였다. Allen과 Rhind(2019)는 학생과 부모를 대상으로 한 심 층면담을 통해 경기장에서 배운 라이프스킬이 교실로 어떻게 전이되는가를 탐색하였다.

국외 연구 성과에 비하면 국내 프로그램 적용과 참여 과 정을 탐색한 연구는 미비하다. 그 이유는 그동안 문화특성 을 반영한 스포츠 라이프스킬 프로그램이 전무했기 때문이 다. 또한 국내에 적용되기 시작한 라이프스킬 연구가 양적 연구에 그치고 있어 참여자들이 프로그램 참여부터 결과까 지 어떤 경험을 하는지에 대한 구체적인 과정을 설명하는 데 한계가 있다. 위와 같은 제한점을 극복하기 위해서는 참여 
자의 경험적 자료에 근거하여 현상을 이해하는 근거이론을 적용할 수 있다.

근거이론은 참여자의 표현 속에서 나타난 의미 있는 사건 들을 참여자의 관점에서 파악하는 방법이다(Strauss \& Corbin, 1998). 사건의 발생과 과정, 결과에 대한 다각적인 측면을 연구하기 위한 방법론으로 인간행동의 상호작용 과 정을 도출하는 방법이다. 근거이론은 검증을 통해 이론을 확인하는 것이 아니라 연구참여자의 경험적 자료에 근거하 여 이론을 창출하기 때문에 참여자의 직관·이해·행동에 대 한 의미 있는 결과를 도출할 수 있다(Lee, 2014).

이러한 접근은 PEAK 프로그램 참여자들의 체험을 내부 자 관점에서 이해하도록 돕고 프로그램 참여 과정에서의 경 험과 의미를 실체적으로 제시할 수 있다. 대학 태권도선수 들이 PEAK 프로그램에 참여하게 된 출발점은 무엇이고 참 여 중 어떠한 맥락과 상호작용을 거쳐 효과를 경험하는지 그 리고 프로그램을 통해 얻는 가치와 의미는 무엇인지 탐색할 수 있다. 이와 같은 연구문제를 해결하기 위해서는 과정 중 심의 질문과 각 질문에 대한 연결고리를 찾을 필요가 있다 (Kim, 2015). 근거이론은 PEAK라는 특정 프로그램에 참 여하는 대상자들의 다양한 상호작용 과정을 밝혀주는 방법 으로 적합하다.

따라서 이 연구의 목적은 근거이론을 기반으로 대학 태권 도선수들의 PEAK 프로그램 참여 과정 전반을 탐색하는 데 있다. 이를 통해 국내에서 개발된 PEAK 프로그램의 효과를 다각적으로 규명할 뿐만 아니라 프로그램 과정 전반에 나타 나는 라이프스킬의 지각-습득(발달)-전이 과정을 구체화할 것으로 기대된다.

\section{연구방법}

\section{연구참여자}

연구참여자는 2019년 1학기 동안 경기도 소재 Y대학에 서 진행된 ‘학습전략 및 라이프스킬(PEAK) 프로그램'에 참 여한 학생운동 선수 12 명이었다. 프로그램 진행과 동시에 연구에도 참여하겠다는 자발적 의사를 밝힌 대상자를 우선 선정하였다. 그리고 프로그램 참여에 대한 성실성, 적극성 과 함께 팀 지도자의 추천도 반영하여 연구참여자를 모집하 였으며, 이 중 연구 참여에 자발적으로 동의한 대상자만을
최종적으로 선정하였다.

초기 연구참여자는 15 명이었으나 이 중 3 명은 결석, 부 상, 개인사유 등으로 인해 중도탈락 하였다. 따라서 최종 참 여자는 12 명(남 $=7$, 여 $=5)$ 이었다. 이들은 모두 대한태권도 협회에 선수로 등록된 Y대학교의 학생 운동선수였으며 평 균 연령은 20.42 세, 선수경력은 평균 7.42 년이었다. 구체 적인 특성은 〈Table 1〉과 같다.

Table 1. Participants

\begin{tabular}{ccccc}
\hline \hline N. & Gender & Grade & $\begin{array}{c}\text { Career } \\
(\mathrm{yrs} .)\end{array}$ & Major award \\
\hline 1 & female & $1^{\text {st }}$ & 7 & - \\
2 & female & $2^{\text {nd }}$ & 10 & $3^{\text {rd }}$ in national championship \\
3 & female & $1^{\text {st }}$ & 9 & $2^{\text {nd }}$ in national championship \\
4 & female & $1^{\text {st }}$ & 7 & $1^{\text {st }}$ in national championship \\
5 & female & $2^{\text {nd }}$ & 6 & $3^{\text {rd }}$ candidate of national team \\
6 & male & $2^{\text {nd }}$ & 9 & $1^{\text {st }}$ in national championship \\
7 & male & $1^{\text {st }}$ & 10 & $1^{\text {st }}$ in national championship \\
8 & male & $1^{\text {st }}$ & 7 & $2^{\text {nd }}$ in national championship \\
9 & male & $1^{\text {st }}$ & 7 & $3^{\text {rd }}$ in national championship \\
10 & male & $1^{\text {st }}$ & 9 & \\
11 & male & $2^{\text {nd }}$ & 9 & $2^{\text {nd }}$ candidate of National team \\
12 & male & $2^{\text {nd }}$ & 8 & $1^{\text {st }}$ in National championship \\
\hline \hline
\end{tabular}

\section{연구절차}

본 연구는 프로그램 진행, 연구 사전 준비, 자료 수집 및 분석, 결과창출 단계를 거쳤다. 본 연구의 배경인 프로그램 은 Y대학교에서 진행된 '학습전략 및 라이프스킬(PEAK) 프로그램' 으로서 2019년 1학기 동안 진행되었다. 연구자 는 프로그램을 설계하고 진행하는 운영자 중 1 인이었으며, 학생선수의 PEAK 프로그램 참여 동기와 참여 과정, 결과, 변화 등을 구체적으로 탐색하고자 본 연구를 계획하게 되었 다. 연구자는 선행연구(Danish, 2002; Danish et al., 1998; Hardcastle et al., 2015; Kwon et al., 2020; Lim, 2019; Lim et al., 2019)를 토대로 PEAK 프로그램을 진행하고, 프로그램을 직접적으로 진행하는 운영자들과 세 미나를 개최하여 정보를 공유하였다.

PEAK 프로그램은 매주 1 회 총 8 주로 구성되었으며 한 회기 당 약 90 분 150 분 정도 소요되었다. 참여자들의 인원 
수에 맞게 워크북을 제작하여 배포하였다. 프로그램 운영자 들은 매주 세미나를 통해 워크북의 내용을 기반으로 피드백 을 주고받았다. 이때 프로그램 운영자들은 라이프스킬 프로 그램 적용 경험이 있거나 관련 연구 경험이 풍부한 스포츠심 리학 박사 또는 박사 과정생이었다. PEAK의 구체적인 절차 는 〈Table 2〉와 같다.

연구 사전 준비 단계에서는 진행되고 있는 PEAK 프로그 램에 대한 전반적인 운영 및 점검, 선행연구 고찰, 연구 설 계, 연구참여자 선정, 전문가 집단 구성 등을 실시하였다. 선 행연구 고찰은 본 연구주제와 부합하는 스포츠 라이프스킬, 학생운동선수, 근거이론 관련 연구들로 진행하였다. 이를 바탕으로 연구의 진행 과정과 방법을 설계하고 연구참여자
를 선정하였다. 전문가 집단은 PEAK 프로그램 운영자를 포 함하여 라이프스킬 연구 경험이 있는 대학교수 1 명, 스포츠 심리학 박사 과정 3 명, 그리고 근거이론 연구 경험이 풍부한 스포츠심리학 박사 1 명 이었다.

자료 수집 및 분석 단계에서는 연구 계획에 입각하여 수집한 자료를 근거이론의 자료 분석법에 따라 분석하 였다. 자료는 연구참여자를 대상으로 수집한 심층면담 원자료와 메모, 프로그램을 진행하면서 작성했던 관찰 일지 등이었다. 심층면담 원자료의 분석은 근거이론의 코딩절차를 통해 이루어졌으며 그 외 자료는 의미가 모 호한 원자료를 해석하거나 자료 분석에서의 진실성과 구체성을 보완하기 위해 활용되었다.

Table 2. PEAK program details

\begin{tabular}{|c|c|c|c|}
\hline Session & Title & \multicolumn{2}{|c|}{ Sample of content } \\
\hline \multirow{3}{*}{1} & Orientation & -Pre-testing and program introduction & -Concept of life skills \\
\hline & Meeting and greeting & -First meeting and finding commonalities & -Making a good first impression \\
\hline & Revision & -Maintain manners during class & \\
\hline \multirow{3}{*}{2} & Self-awareness & "“Finding me" & -What am I like? \\
\hline & Revision & -Understanding the academic calendar and te & chedule \\
\hline & & -Checking report deadlines & \\
\hline \multirow{3}{*}{3} & Finding dream & -My dream graffiti book & -Find my dream \\
\hline & Goal-setting and practice & $\begin{array}{l}\text {-Establishing SMART goals } \\
\text {-Competition objectives }\end{array}$ & -Subject and results objectives \\
\hline & Revision & -Making a revision plan & \\
\hline \multirow{3}{*}{4} & Positive thinking & -Changing your mind & your weaknesses into strengths \\
\hline & Managing emotions & -Understanding and measuring your mind & -Mind control skills \\
\hline & Revision & -Creating learning motivation & -Increasing self confidence \\
\hline \multirow{3}{*}{5} & Enhancing confidence & $\begin{array}{l}\text {-If you can image, it is possible (successful ir } \\
\text {-Achieve your dream }\end{array}$ & gery) \\
\hline & Self-management & -Checking self-management skills & -Daily lifestyle management \\
\hline & Revision & -Presentation methods $\quad$-Managing school & its (graduation, tests, scholarship) \\
\hline \multirow{3}{*}{6} & Appreciating diversity & -Understanding differences & -Defining differences and mistakes \\
\hline & Communication & -Discussion strategies and techniques for con & unication $\quad$-Discuss dilemmas \\
\hline & Revision & -Participate in team projects & -Managing attendance \\
\hline \multirow{3}{*}{7} & Interpersonal relationship & $\begin{array}{l}\text {-Maintaining relationships } \\
\text {-Maintaining personal space and distance }\end{array}$ & -My personal relationship skills \\
\hline & Helping each other & -Giving and helping $\quad$ Expressing thanks & -Throw your worries (game) \\
\hline & Revision & -Obtaining class information & -Telephone etiquette \\
\hline 8 & Final evaluation & -Reviewing the course & -Post-test and interview \\
\hline
\end{tabular}


결과 창출 단계에서는 연구 목적과 취지, 주제에 입각 하여 근거이론 패러다임 모형 추출, 상황적 관계 진술, 그리고 이야기 윤곽을 통해 핵심범주를 도출하였다. 자 료 수집과 분석, 결과 창출 단계에서의 오류와 편향을 방 지하기 위해 전문가 회의를 수시로 개최하였다.

\section{자료수집}

학생선수의 PEAK 프로그램 참여 과정을 탐색하기 위해 심층면담을 진행하였다. 심층면담은 프로그램이 종료된 시 점부터 약 1 개월 가량 진행되었다. 핵심질문(예: 프로그램 을 통해 무엇이 변화하였나요?, 프로그램을 통해 얻게 된 내 용이 일상에도 적용되었나요?)을 시작으로 초기 면담은 개 방형으로 진행하였으며, 점차 연구주제에 접근할 수 있도록 반구조화 면담이 혼용된 방식을 활용하였다(Hong, Sin, Park, \& Park, 2013). 특히 핵심질문을 누락시키지 않으면 서 풍부한 자료를 수집하기 위해 〈Table 3〉의 반구조화 질 문지를 활용하였다.

면담은 개인당 $1 \sim 2$ 회, 회당 약 1 2시간 진행하였다. 참 여자의 편의에 따라 면담 가능한 시간과 장소를 선정하였 다. 모든 면담 내용은 스마트폰을 이용해 녹취하였다. 녹음 된 원자료는 훼손을 막기 위해 한글 프로그램에 전사하였 다. 전사된 원자료를 분석하면서 의미가 모호한 부분은 $\mathrm{SNS}$ 나 유선으로 참여자에게 직접 확인하였다. 더 새로운 내용의 원자료가 나타나지 않고 범주의 속성과 차원이 충분 히 설명된다고 여겨질 때, 자료수집이 포화를 이룬 것으로 판단하고 면담을 종료하였다.

연구자는 심층면담이 진행되는 동안 연구자가 느낀 것이 나 떠오른 아이디어, 참여자의 중요 진술 등을 면담 중 혹은
면담이 끝나자마자 메모하였다. 그리고 프로그램을 진행하 면서는 운영자들과 함께 매 회기 프로그램의 분위기, 과정 등을 기록하였다.

\section{자료분석}

자료분석은 Strauss와 Corbin(1998)의 절차에 따라 개 방코딩(open coding), 축코딩(axial coding), 선택코딩 (selected coding)의 세 단계를 거쳤다.

개방코딩에서는 원자료의 줄단위 분석과 문장·문단 분석 을 통해 개념을 발견한 뒤 유사하거나 의미상 관련이 있다고 여겨지는 개념들을 묶어 하위와 상위범주를 구성하였다. 개 념어를 설정하는 과정에서는 객관적인 시각으로 현상을 해 석하고 그 의미 또한 객관적으로 표출하기 위해 연구자간 협 의(peer debriefing) 과정을 거쳤다. 협의 과정 결과를 바 탕으로 하위범주와 상위범주를 구성한 뒤 각 범주의 속성과 그 속성이 변화하게 되는 차원을 발견하였다.

축코딩에서는 범주들 간의 관계를 밝히기 위해 패러다임 모형을 적용하였다. 이를 위해 하위범주들을 인과적 상황, 맥락적 조건, 중심현상, 중재적 조건, 작용/상호작용 전략, 결과에 연결하여 재배치하였다. 패러다임 모형을 통해 개념 화한 자료들의 관계를 설정하고 하위범주들의 관계를 연결 하였다. 이때 개념화된 중심현상과 시간에 따른 순서 그리 고 결과에 나타난 의미 간의 상호관계를 연결하였다.

선택코딩 단계에서는 참여자들의 중심현상 유지를 위한 핵심범주(core category)를 도출하였다. 핵심범주를 밝히 고 개념을 통합하기 위해 메모, 이야기 윤곽 적기를 활용하 였다. 그중에서 이야기 윤곽(story line)은 시간의 흐름에 따라 변화된 상황들을 추적하는 방법으로서 PEAK 프로그

Table 3. Sample of semi-structured interview

\begin{tabular}{cl}
\hline \hline N. & \multicolumn{1}{c}{ Questions } \\
\hline 1 & What was the image of the program before you participated in this program? \\
2 & How was your mindset before participating in this program? \\
3 & How did you get involved in this program? \\
4 & What is your most memorable part of this program? \\
5 & What prevented or helped you participate in the program? If so, how did you get in the way and helped? \\
6 & How did you benefit from this program? \\
7 & What efforts have you made to participate in this program to the end? \\
8 & What did you do to apply what you learned in this program to your daily life? \\
\hline \hline
\end{tabular}


램 참여에 대한 핵심범주를 찾기 위해 서술하였다.

\section{자료의 진실성}

자료의 진실성을 위해 삼각검증법(triangulation)을 활 용하였다. 삼각검증법 중 학생운동선수 및 스포츠 라이프스 킬, $\mathrm{PEAK}$ 프로그램과 관련된 선행연구 및 이론을 활용하는 이론의 삼각화를 진행하였다. 그리고 심층면담 원자료와 메 모, 관찰 일지 등을 활용하는 자료의 삼각화를 통해 자료분 석의 진실성을 확보하였다.

연구자만의 주관적인 해석으로 인한 오류를 보완하기 위 해 라이프스킬 관련 연구를 수행한 경험이 있는 대학교수 1 명, 박사 과정 3 명, 그리고 근거이론 연구 경험이 풍부한 박 사 1 명의 전문가로 구성된 동료 간 협의(peer debriefing)
를 진행하였다. 그리고 분석된 내용을 직접 연구참여자에게 확인하는 구성원 간 검토(member checking)를 통해 자료 의 의미 왜곡을 방지하도록 노력하였다.

\section{결과}

\section{PEAK 프로그램 참여 과정 개념 및 범주화}

원자료에서 도출된 개념을 명명한 후 상위체계로 범주화 하는 과정을 거쳤다. 이를 토대로 12 개의 상위범주, 30 개의 하위범주, 171 개의 개념이 도출되었다〈Table 4〉. 도출된 자료를 패러다임 모형의 6 가지 구성요소에 배치하여 전체 적인 구조를 파악하였다.

Table 4. Conceptualization and categorization of PEAK program participation

\begin{tabular}{|c|c|c|c|}
\hline Paradigm & Category & Subcategory & Concepts \\
\hline \multirow{7}{*}{$\begin{array}{c}\text { Causal } \\
\text { situation }\end{array}$} & \multirow{4}{*}{$\begin{array}{l}\text { Bad attitude } \\
\text { in class }\end{array}$} & Task & Not doing task, Don't know what the task is \\
\hline & & Class & Absent from class, Absent from class annoying, Not attending class \\
\hline & & Something else & Something different in class, Sleep in class, Cell phone use, Not focused \\
\hline & & Interest & $\begin{array}{l}\text { No interest in class, Presentation omitted, Not preparing for class, Passive participation, } \\
\text { Sitting only behind }\end{array}$ \\
\hline & \multirow{3}{*}{$\begin{array}{l}\text { Helpless daily } \\
\quad \text { life }\end{array}$} & Repetitive routine & Repetition of Exercise-Academic-Relaxation, The same daily routine \\
\hline & & Isolation & Life disconnected from everyday life, Only in dormitory (school) \\
\hline & & Stress & Peer stress, The stress of living in a dorm \\
\hline \multirow{8}{*}{$\begin{array}{l}\text { Contextual } \\
\text { condition }\end{array}$} & \multirow{3}{*}{$\begin{array}{l}\text { Recognizing } \\
\text { the need to } \\
\text { participate } \\
\text { in class }\end{array}$} & $\begin{array}{l}\text { Awareness of student } \\
\text { duty }\end{array}$ & Students must study, Class is the responsibility of the student, Now is the time to study \\
\hline & & $\begin{array}{l}\text { Necessary for the } \\
\text { match }\end{array}$ & $\begin{array}{l}\text { Credit management for participation in competitions, Management of minimum credits } \\
\text { for competition }\end{array}$ \\
\hline & & $\begin{array}{l}\text { Scholarship } \\
\text { maintenance }\end{array}$ & Retention of existing scholarship students, National scholarship, Academic scholarship \\
\hline & \multirow{2}{*}{$\begin{array}{l}\text { Recognizing } \\
\text { the need for } \\
\text { a dual career }\end{array}$} & $\begin{array}{l}\text { Basic education } \\
\text { required }\end{array}$ & $\begin{array}{l}\text { Basic knowledge required, academic achievements important, social life necessary, } \\
\text { good parents }\end{array}$ \\
\hline & & Career preparation & Preparation for employment, thinking about the future, career after retirement \\
\hline & \multirow{3}{*}{$\begin{array}{l}\text { Motivation } \\
\text { for } \\
\text { participation } \\
\text { in the } \\
\text { program }\end{array}$} & $\begin{array}{l}\text { Class strategy } \\
\text { demand }\end{array}$ & $\begin{array}{l}\text { How to Participate in Classes, Changes in Class Attitudes, How to Study Well, How to } \\
\text { Concentrate, Information on School Life }\end{array}$ \\
\hline & & $\begin{array}{l}\text { Awareness of the } \\
\text { need for life skills }\end{array}$ & $\begin{array}{l}\text { Interpersonal relationship improvement, Need for positive thinking, Recognition of the } \\
\text { importance of communication, Improvement of speech ability, Goal setting method, } \\
\text { Timid personality change, Need for self- awareness, Need for time management }\end{array}$ \\
\hline & & $\begin{array}{l}\text { Acquaintance } \\
\text { recommendation }\end{array}$ & Recommendation from a leader, Recommendation from a senior (claimer) \\
\hline $\begin{array}{l}\text { Main } \\
\text { phenomenon }\end{array}$ & $\begin{array}{l}\text { Participation } \\
\text { in the } \\
\text { program }\end{array}$ & $\begin{array}{l}\text { Participate in the } \\
\text { program }\end{array}$ & $\begin{array}{l}\text { Participate according to the given program time, with motives, Participate while } \\
\text { reinforcing the missing time, Participate in programs for each topic }\end{array}$ \\
\hline
\end{tabular}


Table 4. Conceptualization and categorization of PEAK program participation (Continue)

\begin{tabular}{|c|c|c|c|}
\hline Paradigm & Category & Subcategory & Concepts \\
\hline \multirow{7}{*}{$\begin{array}{l}\text { Interventiona } \\
1 \text { conditions }\end{array}$} & \multirow{4}{*}{$\begin{array}{l}\text { Disturbing } \\
\text { factor }\end{array}$} & Schedule & Match schedule, Dinner party, Next class, Department event, Personal schedule \\
\hline & & Training & Difficulty participating, Training ends late, Weight control \\
\hline & & Peers and senior & Seniors' notice, Induction of peers" absence \\
\hline & & Low motivation & Annoyance, Tiredness, injury, Poor physical condition, Decreased concentration \\
\hline & \multirow{3}{*}{ Help factor } & Team support & $\begin{array}{l}\text { Consideration of participation time, Fun to be together, Program recommendation, Help } \\
\text { understanding of the program }\end{array}$ \\
\hline & & School support & Snack support, Program development and support, Providing a comfortable place \\
\hline & & Program leaders & $\begin{array}{l}\text { Player experience empathy, Fun program progression, Easy-to-understand explanation, } \\
\text { Counseling on concerns }\end{array}$ \\
\hline \multirow{6}{*}{$\begin{array}{l}\text { Action/Intera } \\
\text { ction strategy }\end{array}$} & \multirow{3}{*}{$\begin{array}{l}\text { Caring } \\
\text { climate }\end{array}$} & Trust building & $\begin{array}{l}\text { Empathy of the former player, The effort to establish a trust relationship, friendliness, } \\
\text { support and support }\end{array}$ \\
\hline & & Operator effort & $\begin{array}{l}\text { SNS communication, Information delivery, Information search, Periodic contact, Fun } \\
\text { video }\end{array}$ \\
\hline & & Peer interaction & $\begin{array}{l}\text { Peer support, Peer counseling, Empathy, Atmosphere of encouragement among } \\
\text { colleagues }\end{array}$ \\
\hline & \multirow{3}{*}{$\begin{array}{l}\text { Promoting } \\
\text { transfer }\end{array}$} & $\begin{array}{l}\text { Experience } \\
\text { knowledge }\end{array}$ & $\begin{array}{l}\text { Patience, Greeting is polite, Game preparation is goal setting, establishing relationships, } \\
\text { and understanding my main skills and complements }\end{array}$ \\
\hline & & $\begin{array}{l}\text { Perception of } \\
\text { benefits }\end{array}$ & $\begin{array}{l}\text { Improve grades, Learn information about school life, Establish relationships, and help } \\
\text { in choosing a job after retirement }\end{array}$ \\
\hline & & $\begin{array}{l}\text { Connect experience } \\
\text { and knowledge }\end{array}$ & Use of workbooks, Sharing experiences, Group discussion, Video viewing \\
\hline \multirow{9}{*}{ Consequence } & \multirow{4}{*}{$\begin{array}{l}\text { Learning } \\
\text { attitude } \\
\text { change }\end{array}$} & Task execution & Participating in, Submitting, Presenting \\
\hline & & $\begin{array}{l}\text { Improve } \\
\text { concentration }\end{array}$ & $\begin{array}{l}\text { Do not sleep, Concentrate on class, Listen to professors, Do not use mobile phones or } \\
\text { messengers }\end{array}$ \\
\hline & & $\begin{array}{l}\text { Attendance } \\
\text { management }\end{array}$ & Attendance management, Not being late, Reporting before the game in case of absence \\
\hline & & $\begin{array}{l}\text { Academic } \\
\text { motivation }\end{array}$ & $\begin{array}{l}\text { Expectation of improving grades, Self-study, Setting goals, Positive thinking about } \\
\text { school }\end{array}$ \\
\hline & \multirow{5}{*}{$\begin{array}{l}\text { Life skill } \\
\text { change }\end{array}$} & $\begin{array}{l}\text { Building a } \\
\text { relationship }\end{array}$ & $\begin{array}{l}\text { Greeting new people, Finding common interests, accepting other people's opinions, } \\
\text { expressing gratitude, changing positions, acknowledging differences }\end{array}$ \\
\hline & & Self-understanding & Finding my strengths, Knowing my deficits, Understanding my Interests \\
\hline & & $\begin{array}{l}\text { Realizing your } \\
\text { goals }\end{array}$ & $\begin{array}{l}\text { Acquisition of certification, Weight control, Exercise planning, Future career } \\
\text { preparation, Game preparation plan }\end{array}$ \\
\hline & & Think positive & $\begin{array}{l}\text { Turning shortcomings into strengths, Winning games, Solving conflicts with senior } \\
\text { colleagues, Overcoming frustration }\end{array}$ \\
\hline & & Life management & $\begin{array}{l}\text { Sleep early and wake up early, Healthy eating habits, Healthy weight control, Stress } \\
\text { management }\end{array}$ \\
\hline
\end{tabular}

\section{PEAK 프로그램 참여 과정 패러다임}

원자료의 개방코딩을 통해 도출된 개념과 상위범주, 하 위범주를 중심으로 축코딩을 진행하였다. 축코딩을 통해 인 과적 상황, 맥락적 조건, 중심현상, 중재적 조건, 작용/상호 작용 전략, 결과의 코딩 패러다임으로 각 범주들을 연결시 켰다. 이어 선택코딩을 통해 핵심범주를 도출하여 PEAK 프 로그램 참여 과정과 의미를 도출하였다.

\section{인과적 상황}

인과적 상황은 중심현상이 발생하도록 이끄는 구체적인 사건이다(Park \& Shin, 2017). 이 연구의 중심현상은 'PEAK 프로그램 참여하기'이다. 이에 영향을 미치는 인과 적 상황은 ‘좋지 않은 수업태도'와 ‘무기력한 일상생활’ 이었 다. 
좋지 않은 수업태도

다수의 참여자는 수업을 들어야 하는 이유를 찾지 못하고 있었다. 수업에 대한 부정적이고 소극적인 인식은 과제 불 이행과 수업 불참, 딴 짓하기, 무관심 등으로 이어졌다. '운 동선수는 운동만 잘하면 된다.'는 고정관념을 가지고 있었 기 때문에 선수로서의 목표에만 집중한 채 학업은 등한시하 였다.

"제 주변 훈련단들은 다 들어가서 자거나 게임하거나 (수업에) 안
들어가요. 다른 종목 애들도 다 태도가 나블걸요? 예전에 교양 교수
님은 방해되니까 아예 들어오지 말라고 했어요." (참여자 3)

"수업 들으러 가는 게 너무 귀찬아요. 저는 진로가 운동 쪽이니까운 동에만 더 집중할 수 있게 해주면 좋겠다고 생각하거든요. 막상 수 업에 들어가도 집중하기 힘들고 관심도 없어요. 보통 수업시간에는 훈련단 친구들이랑 딴 짓하거나 핸드폰 게임 해요." (참여자 6)

\section{무기력한 일상생활}

반복되는 훈련과 수업으로 이루어지는 선수들의 일상은 너무나 단조로웠다. 더욱이 수업 외에 모든 시간을 운동부 동료들과 함께 생활하면서 선배·동기·후배와의 갈등과 스 트레스도 겪었다.

“훈련단은 매일 똑같아요. 눈뜨면 새벽 운동하고 아침 먹고. 오전수 업 들어가서 자고 점심 먹고. 오후수업 갔다가 오후 운동가고, 저녁 먹고, 야간운동 가고. 이게 반복되니까 너무 스트레스 받아요. 하루 하루 그냥 의미 없이 흘러가는 것 같아요." (참여자 1)

"저희는 훈련단끼리만 생활하고 놀아요. 일반학생은 누군지 잘 모 르겠어요. 그래서 시합 갔다 오면 과제가 뭔지도 잘 모르겠고 수업 에 참여하는 게 힘들어요. 학교도 재미없고요." (참여자 11)

참여자들은 운동이 삶의 축이 된 생활을 하고 일반 학생 과 교류할 기회가 적다 보니 타인과의 관계 형성이나 다양한 경험을 하지 못했다. 이러한 반복된 생활로 인해 참여자들 은 무기력에 빠지게 된다.

\section{맥락적 조건}

맥락적 조건은 중심현상에 영향을 미치는 사건이다. 작 용/상호작용 전략을 통해 반응해야 하는 상황이나 문제들을 만들어낸다(Shin \& Kim, 2003). 이 연구에서는 'PEAK 프 로그램 참여'라는 중심현상을 가져오는 맥락적 조건으로
‘수업 참여의 필요성 인식', '이중경력의 필요성 인식', 그리 고 '프로그램 참여 동기' 가 도출되었다.

수업 참여에 대한 필요성 인식

참여자들은 ‘평균 학점 2.0 이하는 시합 출전 금지' 라는 규정 때문에 수업 참여의 필요성을 인식하기 시작하였다. 시합 출전에 학점이 영향을 주고 운동선수로서 진로에 대한 고민이 커지는 분위기(Park, Won, \& Cho, 2016)는 참여 자에게 최소한의 수업 참여와 학점 관리의 필요성을 체감하 게 하였다.

"평균 학점이 2.0 이상이 안 되면 시합에 출전할 수 없어요. 학생의 역할을 다 하기전에는 시합도 뛰지 말라는 것 같아요. 어쨌든 시합을 뛰기 위해서는 학생으로서 성적관리를 안 할 수 없어요." (참여자 4)

“저는 전액 장학생인데 최저학점인 2.0 이하로 떨어지면 장학금도 못 받고 시합도 못 뛰어요. 그래서 수업을 열심히 들어야 해요." (참 여자 8)

몇몇 참여자들은 학생과 선수의 역할이 따로 있다고 생각 하였다. 실업팀에 가기 전에는 수업에 참여하여 선수의 역 할과 학생의 역할을 모두 충실히 해야 한다고 인식하고 있었 다.

“등록금이 너무 아까워요. 수업료를 냈으니까 그만큼 배우는 것도 있어야 되고, 지금이 아니면 못 배우는 것들이 있지 않을까요? 조금 열심히 하니까 학교에서 성적 장학금은 못 받아도 국가장학금은 받 을 수 있더라고요." (참여자 9)

이중경력 필요성 인식

은퇴 후 진로에 대한 준비가 되지 않아 어려움을 겪는 지 인을 보면서 참여자들은 은퇴 이후의 경력에 대해 고민하였 다. 그리고 운동이 아닌 다른 길을 가기 위해서는 관심 분야 에 대한 정보가 필요하다는 생각이 커졌다.

“친한 선배가 부상으로 갑자기 운동을 그만뒀는데 뭘 해야 할지 막 막하고 준비가 안 되어 있다고 하는 걸 듣고 저도 갑자기 불안해졌 어요." (참여자 2)

"운동한 사람은 무식하고 멍청하다고 생각하는 사람이 많은 것같아 요. 운동하긴 했지만 멍청하다고무시당하고 싶지는 않아요. 운동 말 고도 내가 잘 하는 것, 할 수 있는 것들을 찾고 싶어요." (참여자 5) 


\section{프로그램 참여 동기}

참여자들은 수업시간에 자발적인 학습을 해본 경험이 적 었다. 수업 참여나 과제 작성법과 같이 학교생활에 대한 정 보가 필요했으나 대인관계나 사귐이 넓지 않아 어려움이 있 었다. 이로 인해 참여자들은 점차 관계 확장이나 교류를 위 한 라이프스킬의 필요성을 인식하였다.

"수업에 열심히 참여하고 싶은데 어떻게 하는지 모르겠어요. 선배 들도 잘 모르니까 누구한테 물어봐야할지도 모르겠고. 이거(프로그 램)하면 배울 수 있을 거라고 기대했어요." (참여자 7)

"저는 너무 소극적이고 불안감을 많이 느끼는 것 같아요. 고치고나 아질 수만 있으면 방법을 배우고 싶어요." (참여자 6)

참여자들은 스스로 수업 참여 전략과 라이프스킬 개발의 필요성을 느껴 프로그램에 참여하기도 했으나 팀 내 지도자 나 선배·동료 등 지인의 추천 또한 참여 동기가 되었다.

"선배가 이런 프로그램 있는데 본인도 프로그램 들었었다고 도움이 많이 되었다고 하더라고요. 저랑 같이 운동했던 선배가 참여해보라 고 추천하니 왠지 더 신뢰가 가고, 해야 할 것만 같고." (참여자 10)

\section{중심현상 : PEAK 프로그램 참여하기}

중심현상이란 작용/상호작용 전략에 의해 반복적으로 조 절되는 중심 사건으로, '무엇을 경험하고 있는가?'에 대한 답이다(Yu, Jung, Kim, \& Kim, 2018). 이 연구에서 중심 현상은 'PEAK 프로그램 참여하기' 로 나타났다.

“프로그램을 하고 싶다는 생각이 드니까 기간 동안 쭉 참여했던 거 같아요. 시합이나 학과 일정이 있으면 따로 보강하기도 했고요. 프 로그램 중간 중간자기 점검하는 내용이 포함되어 있어 주제들이잘 기억났던 거 같아요." (참여자 8)

“저희는 중간에 학과 일정하고 운동부 일정이 겹쳐서 빠지는 주차 가 많았는데 선생님과 보강할 수 있는 날짜를 정해서 끝까지 마쳤던 거 같아요." (참여자 4)

참여자들은 프로그램에 대한 동기가 형성되면서 다 양한 모습으로 프로그램에 참여했다. 운동 전· 후 정해 진 시간에 맞춰 동료와 함께 참여하였고 시합이나 학과 일정으로 인해 결손 된 내용은 보강을 통해 채웠다.

\section{중재적 조건}

중재적 조건은 중심현상과 관련하여 작용/상호작용 전략 을 촉진하는 역할을 한다(Strauss \& Corbin, 1990). 이 연 구의 중심현상인 'PEAK 프로그램 참여하기' 에 대한 중재적 조건으로는 방해요인과 도움요인이 추출되었다.

방해요인

참여자들은 훈련·시합·수업 등 빈틈없이 반복되는 일정 때문에 마음대로 시간을 활용할 수 없었다. 이러한 외적 원 인뿐만 아니라 자신의 컨디션 저하, 부상 또한 프로그램 참 여를 방해하였다.

"운동이 끝나면 너무 힘들어서 가기 싫었어요. 선배가 프로그램 가 지말고 나가서 밥 먹자고 하면 고민이 많이 되었어요." (참여자 12)

"저희는 아직 선수니까 시합 뛰려면 체중조절 해야 되고. (중략) 프 로그램 참여하는 날 시합 뛰고 회식을 했어요. 시합일정은 협회에서 정하고, 회식은 팀 전체니까 제 마음대로 날짜를 조절할 수 없잖아 요." (참여자 5)

도움요인

방해요인과는 반대로 팀 동료와 학교의 지원, 프로그램 운영자의 조력은 프로그램 참여에 도움이 되었다. 팀에서는 프로그램에 적극적으로 참여할 수 있도록 시간을 할애해주 었고 함께 한 동료 때문에 흥미로운 분위기가 조성되었다.

"훈련단에서 많이도와준 것 같아요. 코치님이 이거(프로그램에 참여) 하라고 추천해주시고, 운동 끝나고 씻고 가라고 조금씩 일찍 끝내주 셨어요. 덕분에 마음 편하게 프로그램에 올 수 있었죠." (참여자 12)

"운동 끝나고 오면 간식이 있어서 너무 좋았어요. 배고프면 집중이 안 되잖아요. 간식을 먹으면서 동기들이랑 재미있게 놀고 간다고 생 각하면서 참여한 거 같아요." (참여자 3 )

특히 프로그램 운영자는 프로그램 개발과 지원뿐만 아니 라 프로그램의 전 과정에서 참여자들을 독려하는 역할을 하 였다. 이러한 조력과 지원은 참여자들이 프로그램에 참여하 도록 도움을 주었다.

"저희들 일정 배려해주시고 한주 어떻게 지냈는지 물어봐 주시고 좋은 자료도 많이 주셔서 너무 좋았어요. 학교 선배로서 배울 점도 많았고요." (참여자 10) 
"선생님들이 너무 좋았어요. 어려운 선생님이 아니라 먼저 운동을 그만둔 인생 선배 같은 느낌이어서 궁금한 것도 많이 물어보고 경험 을 들을 수 있었어요." (참여자 2)

\section{작용/상호작용 전략}

작용/상호작용 전략이란 중심현상에 대처하기 위해 취하 는 의도적인 행위로서 중심현상을 다루고, 조절하고는 실제 행동이다(Yu et al., 2018). 참여자들은 중심현상을 유지하 기 위해 '캐어링 분위기'와 '전이 촉진'을 활용하였다.

\section{캐어링 분위기}

캐어링 분위기(caring climate)란 특정 활동 내 구성원 들로 인해 만들어지는 동기적 분위기로서 활동 참여에 대한 헌신과 격려, 사회적지지, 상호작용 등으로 인해 형성되는 분위기이다(Shim, 2012).

참여자들은 프로그램이 진행되는 동안 운영자와 동료를 통해 캐어링 분위기를 경험하였고 이러한 분위기는 프로그 램 참여를 지속하는 동력이었다. 운동선수 출신의 프로그램 운영자는 참여자들과 공감하고 고민을 상담해 주는 등 조력 자 역할을 해주었다.

"운동선수는 공부를 못 하는 게 당연하다고 생각했는데 선생님들도 선출(선수 출신)에 박사까지 하시는 걸 보니까 우리도 할 수 있을 것 같은 생각이 들었어요. 이번 학기 성적은 포기하려고 했는데 선생님 이 할 수 있다고 응원을 많이 해줘서 포기하지 않은 것 같아요." (참 여자 3)

"가끔 다른 것이 바빠서 까먹을 수 있잖아요. 근데 단체 (카)톡방에 서 스케줄을 물어보고, 알려주고 수업관련 정보를 알려줘서 좋았어 요." (참여자 11)

참여자들은 함께하는 동료와의 상호작용 때문에 적극적 으로 프로그램에 참여할 수 있었다. 훈련과 수업, 생활까지 함께하는 동료들은 고민 상담과 공감, 격려 등을 통해 프로 그램 참여를 지지하였다. 이러한 상호작용은 프로그램 참여 를 촉진하는 전략이 되었다.

“동기들이랑 같이 참여했기 때문에 더 열심히 재미있게 참여했어 요. 살 빼서 힘들었는데 같이 가자고 해주고 가방도 대신 들어줬어 요." (참여자6)
"저 혼자 하라고 했으면 못 했을 걸요. 저희는 다 같은 방을 쓰고 있 어서 늘 같이 움직이게 되거든요. 제가 가기 싫은 날에 친구들이 가 면 싫어도 같이 가게 되고 했던 거 같아요." (참여자 1)

\section{전이 촉진}

전이 촉진을 구성하는 하위범주로는 경험 지식, 혜택 지 각, 경험과 지식 연결이 도출되었다. 경험 지식은 참여자들 이 선수 경험을 통해 체득한 라이프스킬을 파악하는 과정이 다. 혜택 지각은 라이프스킬을 일상에 적용했을 때 얻을 수 있는 이점을 알게 되는 단계이다. 경험과 지식연결은 라이 프스킬 전이를 위해 활용되는 워크북이나 조별 토론, 영상 시청이다.

"운동하면서 운동만 배운 것이 아니고 일상생활에 필수적인 것들도 배웠다는 걸 알았어요. 프로그램 할 때 운동에서 배운 라이프스킬을 일상생활에서 적용해보는 걸 항상 했었거든요. 그게 도움이 많이 되 었어요." (참여자 4)

"그동안 운동이랑 공부는 따로라고 생각했어요. 그런데 우리가 운 동하면서 하는 규칙이나 행동들도 공부나 일상생활에 쓰면 플러스 가 된다는 걸 알았어요." (참여자 5)

참여자들의 경험과 지식을 연결하는 촉매제가 된 워크북 은 라이프스킬 전이의 중요한 도구가 된다. 워크북은 의도 적으로 프로그램을 제공하는 것뿐만 아니라 참여자들의 생 각을 정리하고 공유하는 데 활용되었다. 직접 생활에 적용 해 볼 수 있도록 주제별로 그리기, 쓰기, 생각하기, 토론하기 와 같은 내용을 포함하였다. 이러한 활동을 통해 배운 내용 을 잊어버리지 않고 바로 일상이나 수업으로 전이시킬 수 있 도록 격려하였다. 또한 참여자들이 어려워했던 과제 작성 법, 출결 관리, 학점 관리 등 학교생활에 필요한 정보들도 점 검할 수 있도록 하였다.

"일반수업이랑 다르게 워크북을 하니까재미있었어요. 특히 운동할 때 지금 해야 하는 것, 이번 주에 해야 하는 것, 더 긴 기간 동안 해야 하는 걸 적어보고 진짜 해보려고 노력했거든요. 생각보다 어렵지는 않더라고요." (참여자 8)

"워크북에 나온 것처럼 수업시간에도 미리 과제 해야 하는 기간을 생각하고 단계별로 하니까 의욕이조금은 생기는 거 같아요." (참여 자2) 


\section{결과}

결과란 중심현상에 대한 반응으로 선택된 작용/상호작용 전략이 초래한 것이다. 이 연구에서 작용/상호작용으로 인 해 나타난 결과는 '학습태도의 변화'와 '라이프스킬의 변화' 였다.

\section{학습태도의 변화}

프로그램을 통해 참여자들은 적극적으로 수업에 참여하 며 학점을 관리하는 등 능동적인 학습태도를 가지게 된다. 수업 시 핸드폰을 사용하지 않고 발표자의 말에 귀를 기울이 며 조별 활동에 참여하는 등 적극적인 태도로 변화했다.

"수업을 열심히 안 들어서 항상 어려웠는데 조금만 집중해보니 내 용이 꽤 재밌더라고요. 원래 맨 뒤에서 핸드폰을 하거나 잠을 잤는 데 지금은 그래도 한 두 칸 앞에 앉아서 수업을 들어요. 뿌듯합니다 (웃음)." (참여자 9)

학습태도의 긍정적인 변화는 자연스럽게 학점 관리로 이 어졌다. 시험에 대비하기 위한 공부를 스스로 하기 시작했 고 성적 향상에 관심을 가졌다. 참여자들은 노력에 대한 기 대를 운동만이 아닌 학업에서도 느끼게 되었고 자신에 대한 기대는 더 나은 학습태도로 확장되었다.

"이번 학기 성적이 기대돼요. 지난 학기에 학점 평균이 2.2여서 코 치님께 혼났는데 이번에는 국가장학금도 받을 수 있을 것 같아요." (참여자 7)

"운동은 잘하니까 당연히 공부는 못해도 된다고 생각했는데 (중략) 더 힘든 운동도 잘하는데 마음먹으면 공부도 잘 할 수 있다고 생각 해요." (참여자 5)

\section{라이프스킬의 변화}

프로그램을 통해 참여자들은 관계 맺기, 자기 이해하 기, 목표설정하고 실천하기, 긍정적 생각하기, 그리고 생활 관리하기 등의 라이프스킬을 점검하고 일상생활에 활용하게 되었다. 즉 참여자들은 프로그램 참여 후 다양 한 라이프스킬의 변화를 경험한 것으로 나타났다. 특히 몇몇 참여자들은 타인에게 다가가 관계를 맺는 라이프 스킬이 상당히 향상되었음을 언급하였다.

“전에는 교양 수업할 때 조별과제가 제일 싫었어요. 모르는 사람이 랑 어색해서 (중략) 지금은 먼저 다른 학과 친구에게 다가가고, 같이
게임도 하면서 새로운 친구들을 많이 사귄 것 같아요." (참여자 6)

"우리(훈련단)끼리만 다니다 보면 다른 학과 애들을 전혀 모르는데 그나마 교양 수업을 할 때 알게 되거든요. 이번 학기 교양 수업이 많 아서 걱정했는데, 프로그램에서 배운 '다가서기', '공통 관심사 찾 기' 전략 같은 것을 활용해봤어요." (참여자 4)

프로그램 전 참여자들은 운동이 아닌 자신이 원하는 목표 를 이루기 위해 계획을 세우고 실행하는 것을 어색해했다. 그러나 프로그램 이후에는 자신의 목표를 이루기 위해서는 무엇이 필요하고 어떤 것들을 준비해야 하는지 스스로 계획 하는 능력이 생겼다. 단기·중기·장기목표를 세우고 실천하 는 등 긍정적인 라이프스킬의 변화가 나타났다.

“대학에 오기 전에는 대학교에 입학하는 게 꿈이고 목표였는데, 대 학에 와서는 뭘 어떻게 해야 하는지 막막했어요. 이 프로그램에 참 여하고 나서 내가 좋아하는 게 뭔지 알게 됐어요. 다른 사람들에게 뭔가를 알려주는 거요." (참여자 8)

"지도자를 하기 위해서는 스포츠지도사 자격증이 필요하다는 생각 을 했어요. 우선 필기부터 공부하고 면접이랑 연수도 준비해야겠어 요." (참여자 10)

자신의 장·단점을 파악하고 단점을 장점으로 변화시키려 는 연습을 통해 긍정적 생각이 향상되었다. 이러한 라이프 스킬은 학교뿐만 아니라 운동에도 활용되었다. 팀에서 일어 나는 갈등 상황을 긍정적으로 해석하면서 자신의 스트레스 도 줄어들었다.

"A선배가 너무 싫었어요. 수업시간에 저는 앞에 앉으라고 하고 그 선배는 뒤에서 게임했거든요. 지금은 앞에서 공부하면 더 많은 것을 배울 수 있다고 좋게 생각하려고요. 어쩌면 후배를 공부시키려는 좋 은 선배일지도 모르겠네요. (웃음) 생각을 조금만 바꾸니까 스트레 스도 줄어드는 것 같아요." (참여자 12)

이러한 과정을 거쳐 도출된 패러다임 모형은 〈Fig. 1〉과 같다.

\section{PEAK 참여 과정에 대한 기술}

상황적 관계 


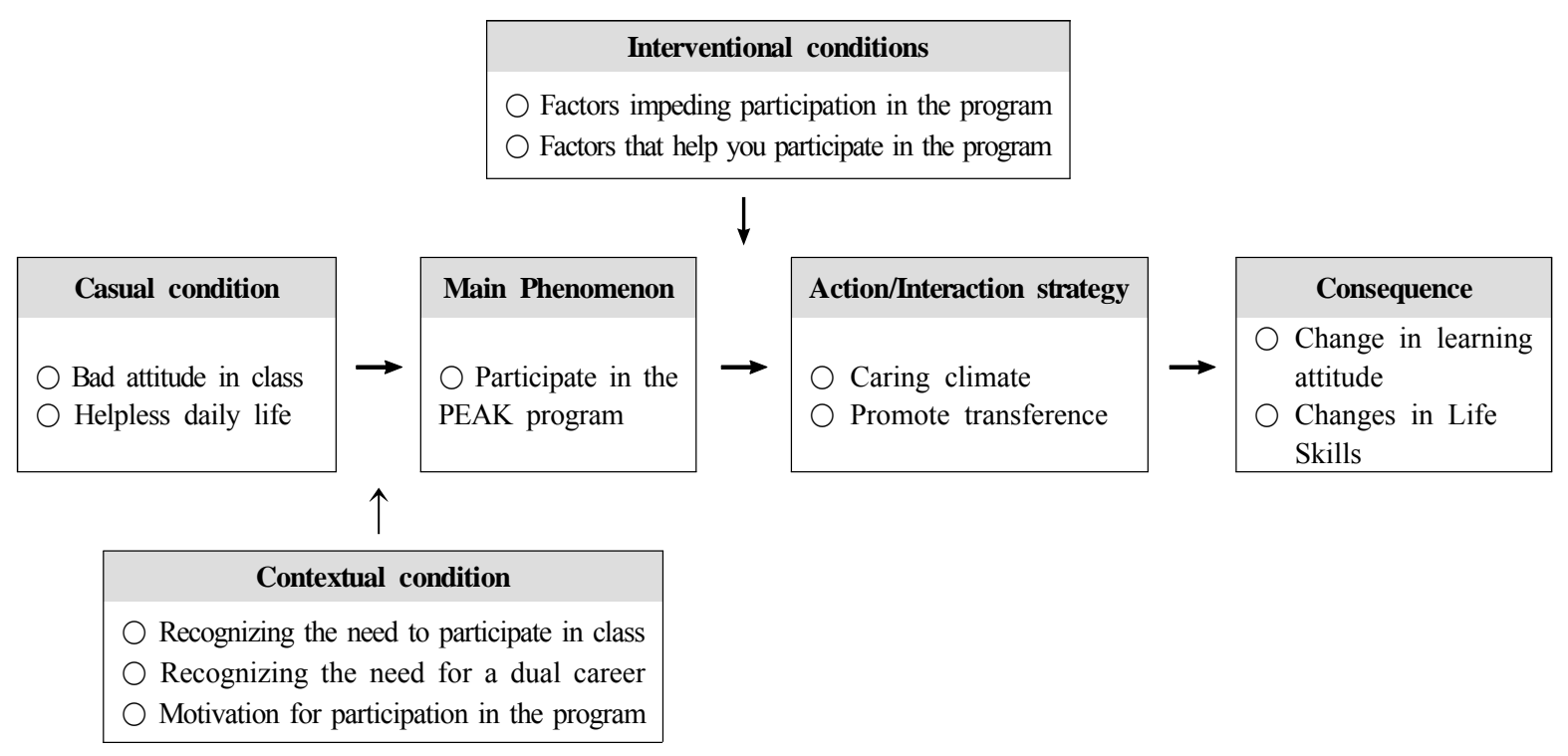

Fig. 1. Paradigm model of PEAK program participation

상황적 관계는 중심현상을 유발하는 인과적 상황과 중심 현상에 영향을 미치는 맥락적 조건과의 관계를 밝히는 것이 다. 이 연구의 중심현상인 'PEAK 프로그램 참여하기'는 인 과적 조건인 '좋지 않은 수업태도'와 ‘무기력한 일상생활'에 영향을 받고 있다. 이와 같은 인과적 조건은 '수업 참여 필요 성 인식', '이중경력 필요성 인식', ‘프로그램 참여 동기’라 는 맥락적 조건이 함께 반영되었다. 따라서 중심현상인 'PEAK 프로그램 참여하기'는 좋지 않은 수업태도, 무기력 한 일상생활, 수업 참여 및 이중경력 필요성 인식, 그리고 프 로그램 참여 동기에 의해 이루어졌다.

\section{이야기 윤곽을 통한 핵심범주: 학습능력 향상과 라} 이프스킬 전이 가능성 확인

이야기 윤곽(story line)은 연구의 중심현상에 대한 서술 적 진술인 이야기를 개념화하는 과정이다(Kim, 2015). 연 구에서 관심을 가진 사건에 '무엇이 일어나고 있는지'를 설 명한다. 이 연구에서는 대학 태권도선수의 PEAK 프로그램 참여의 이야기 윤곽을 전개하고, 이를 통해 핵심범주를 발 견하였다.

대부분의 참여자들은 운동과 수업 참여, 선수단과 기숙 사 생활 등 반복되는 일상에 지쳐 무기력한 생활을 이어가고 있었다. 무기력함은 학업으로까지 이어져 좋지 않은 수업
태도로 나타났다. 수업에 잘 참여하지 않거나 과제를 제출 하지 않는 등 전반적으로 수업에 소극적인 태도를 보였다. 운동만을 중시하는 참여자들의 인식은 부정적인 수업 태도 로 이어졌다.

그러나 선수들의 학습권 보장에 대한 분위기가 커짐에 따 라 시합 출전을 위해서는 최소한의 학점을 취득해야 했다. 시합에 출전하기 위해서는 2.0 이상의 평균 학점을 받아야 하고 장학금을 받기 위해서라도 학점 관리의 필요성을 느끼 게 된다. 그리고 기초 학업 능력이 갖추어지지 않으면 운동 을 그만둔 이후 다른 진로를 찾거나 직업을 선택하는 데 어 려움을 겪을 것으로 예상했다.

주변에 운동을 그만둔 학생들이 진로 때문에 방황하 는 모습을 보면서 은퇴 이후를 위해서는 기초학력과 이 중경력이 필요함을 느겼다. 특히 참여자들은 정해진 운 동부 내 구성원과 생활하는 시간이 절대적으로 많아서 다른 학과생과 관계를 형성했던 경험이 부족했다. 이에 운동선수로서 필요한 심리기술이나 학업 정보뿐만 아니 라 대인관계 기술과 사회적 기술도 필요로 하게 되었다. 그러나 필요성을 인식하였음에도 불구하고 어떻게 수업 에 참여해야 하는지, 라이프스킬을 어떻게 개발해야 하 는지는 알지 못했다. 이때 지도자와 선배, 주장의 추천 으로 'PEAK 프로그램'에 참여하게 되었다. 자신과 함께 
운동하고 생활했던 주요 타자의 추천은 강력한 프로그 램 참여 동기가 되었다.

참여자들은 '선수는 공부와 거리가 멀다'고 스스로 생각 해온 탓에 기본적인 수업 예절과 수업 참여방법, 과제 작성 방법, 학사 정보에 대해 모르고 있었다. 따라서 참여자들의 수준에 맞게 PEAK 프로그램은 강의식이 아닌 이해와 활용 방식을 택했다. 참여자들이 운동을 통해 습득한 라이프스킬 을 발견하고 이를 어떻게 수업이나 일상에 전이시킬 수 있는 지 학습하였다. 프로그램 참여 전 대상자들은 스스로 운동 을 통해 운동만을 익혔다고 생각할 뿐 다양한 라이프스킬도 함께 체득되었음을 인지하지 못했다. 이에 프로그램 운영자 들은 그들의 경험에 빗대어 참여자들이 운동을 통해 얻은 강 점과 라이프스킬을 발견하고 이를 활용할 수 있는 전략을 제 공하였다.

프로그램 참여에는 방해요인과 도움요인이 공존했다. 먼 저 참여자들의 생활 특성상 시합과 운동부 일정, 학교 및 학 과 행사, 훈련, 부상 등은 프로그램 참여를 방해하였다. 프로 그램에 가고 싶어도 선수단 분위기로 인해 참여하지 못할 때 도 있었고 운동부 일정과 시합이 겹칠 때도 정상적으로 참여 가 어려웠다. 이러한 결손이 많아질 때면 운영자들은 메신 저를 통해 참여자들과 보강할 수 있는 시간을 확보하고 프로 그램 참여도와 흥미도에 대한 지속적인 피드백을 제공하였 다. 이러한 운영자와의 라포(rapport) 형성과 프로그램에 참여하는 동료들의 공감, 격려와 지지 분위기는 프로그램 참여에 도움을 주었다.

프로그램에 참여할 수 있도록 시간을 조정해 주는 팀의 배려와 학교의 지원 그리고 운영자의 프로그램 진행 방식 또 한 쉽고 흥미로워 프로그램을 지속할 수 있는 중재조건이 되 었다. 프로그램 초기에 몇몇 참여자들은 비자발적 참여로 소극적이었다. 그러나 선수 출신의 운영자가 참여자들이 처 한 상황과 감정을 이해하는 상호작용을 통해 라포가 형성되 었다. 운영자는 참여자들이 일상과 학업, 선수로서 필요한 부분을 준비할 수 있도록 영상, 자료 등 다양한 콘텐츠를 제 공하였다. 특히 성적 향상을 위한 출결 관리, 과제 작성 방법 등 수업에서 직접 사용할 수 있는 방법을 제시하였다. 운영 자들은 프로그램 외적으로도 응원과 고민상담 등 적극적인 지지를 표현함으로써 캐어링 분위기가 형성되었다. 이러한 분위기는 참여자들의 프로그램 참여를 촉진하였다.

프로그램의 내·외적인 지원으로 인해 참여자들은 운동을 통해 체득한 라이프스킬을 발견하게 되고 일상에 전이시키
는 과정을 체험하였다. 이러한 전이 과정에서 워크북은 참 여자들의 라이프스킬을 일상으로 확장 시킬 수 있는 매개체 가 되었다. 워크북은 스포츠 상황과 일상으로 나누어 해보 기와 평가로 구성되었다. 콘텐츠는 그리기·쓰기·생각하기· 토론하기·발표하기로 구성되었다. 참여자들은 워크시트를 통해 라이프스킬 덕목을 이해하고 실천하였다.

참여자들은 PEAK 프로그램을 통해 적극적인 수업 참 여와 학점 관리 등 학습태도에서 긍정적인 변화를 나타 냈다. 먼저 수업시간에 집중하고 경청함으로써 학점 향 상을 기대하게 되었다. 자신에 대한 기대는 운동이 아닌 또 다른 목표를 설정하게 하였고 목표 달성을 위해 시간 과 일상을 관리하였다. 참여자들의 라이프스킬은 일상 으로 전이되어 자기이해하기, 목표설정하기, 긍정적 생 각하기, 관계 맺기, 생활 관리하기에 영향을 주었다. 자 기이해를 통해 자신의 장-단점을 알고 강점을 개발하는 능력이 향상되었다. 그리고 꿈을 실현 가능한 목표로 만 들고 하나씩 실천해가는 목표 달성하기를 통해 행동의 변화가 나타났다. 새로운 만남을 어색해했으나 먼저 다 가가 인사하며 공통 관심사를 찾는 등 관계 맺기에도 변 화가 시작됐다. PEAK 프로그램 참여는 단점을 극복할 뿐만 아니라 단점을 장점으로 바꾸고 '나도 할 수 있다' 는 믿음을 심어 주었다. 이러한 생각의 전환은 운동을 통 해 배운 라이프스킬이 일상에도 전이될 수 있음을 확인 시켜 주었다. 결과적으로 PEAK 프로그램 참여를 통해 나타난 핵심범주는 "학습능력 향상과 라이프스킬 전이 가능성 확인”이었다.

\section{논의}

이 연구의 목적은 근거이론을 통해 대학 태권도선수들의 PEAK 프로그램 참여 과정을 탐색하는 것이었다. 그 결과 중심현상은 'PEAK 프로그램 참여하기’로 나타났고 핵심범 주는 "학습능력 향상과 라이프스킬 전이 가능성 확인" 이었다.

첫째, 프로그램 참여의 인과적 상황과 맥락적 조건이 순 차적으로 PEAK 프로그램 참여 동기를 형성하였다. 참여자 들은 선수이기 전에 대학생이었지만 학업의 필요성을 느끼 지 못한 채 소극적인 수업 태도를 보였다. 그러나 은퇴 후 진 로에 대한 준비가 없어 힘들어하는 주변 동료선수들을 보며 점차 기초학력과 이중경력의 필요성을 실감하게 되었다. 우 
리나라 학생선수는 대부분 성공의 기준을 경기력과 시합 성 과에 두기 때문에 공부보다는 훈련에 매진한다(Kim \& Chung, 2012). 선수로서의 가치가 더 크다고 인식하기 때 문에 운동이 최우선이어야 한다는 강박에 휩싸인다(Park \& Shin, 2017). 이렇듯 학생선수들은 공부와 운동이라는 두 가지 선택의 기로에서 당장 성과를 만들어내기 위해 훈련에 매진하지만 결국 자신의 암울한 미래를 직관적으로 깨닫는 순간 또 다른 미로에 빠진다.

둘째, 참여자들은 이중경력과 기초학력의 필요성을 자각 하면서 프로그램에 참여하게 된다. 이전까지 모든 체육특기 자 관련 제도들은 정규수업에 참여하지 않아도 상급학교에 진학할 수 있었다. 이러한 제도는 학생선수들로 하여금 정 규수업 참여에 대한 필요성을 불식시키는 원인이었다 (Kang, 2015; Kim, Kim, \& Kim, 2014). 그러나 최저학 력제가 도입되고 일정 학점 이상이 되어야 시합에 출전할 수 있게 되자 참여자들은 최저 학점의 필요성을 느꼈다. 선수 들을 PEAK 프로그램 참여로 이끈 또 하나의 원인은 이중경 력의 필요성이었다. 대학생들에게 진로에 대한 관심은 졸업 후 직업 선택으로 이어진다. 학생선수들에게도 이 과정은 중요하다. 하지만 이들을 위한 환경 여건과 정보가 부족하 다(Kim \& O, 2017), 학생선수의 진로 선택이 제한되는 이 유는 대부분 기초 소양 및 정보 부족 때문이다. 특히 은퇴 이 후 관심 분야에 대한 정보가 부족한 학생선수들은 진로 결정 에 소극적이고 이러한 태도는 경력 전환에 부정적으로 작용 한다(Kim, Lee, \& Jang, 2015).

학생선수들은 어린 나이부터 공부와 운동 사이에서 균형 을 이루기보다 지나치게 편중된 목표에 열중하는 경향이 강 하다. 이렇다 보니 이른 시기부터 이미 공부에는 자신감이 없다. 이 때문에 책이나 교실 환경에 직면하면 거부반응을 일으킨다(Hong, 2005; Kim, 2012). 참여자들 또한 오랜 시간 운동만 해온 터라 다른 진로에 대한 정보나 학업, 학점 관리 경험이 매우 부족했다. 다행히 정보를 필요로 하는 참 여자들의 갈증은 $\mathrm{PEAK}$ 프로그램 참여 동기로 이어졌다.

셋째, 참여자들은 라이프스킬의 필요성을 절감하면서 프 로그램에 참여하였다. 대학 운동선수들은 대부분 유년 시절 부터 합숙·단체생활을 경험한다. 이러한 운동부 문화는 제 한된 대인관계 때문에 사회적 활동에 대한 결핍을 야기한다 (Kim, 2011; Yu \& Yi, 2004). 고립된 섬이라 불리는 운동 부 문화는 그들을 고립된 환경에 놓이게 한다. 고립된 환경 에 있다 보니 스트레스는 물론 다른 학생들에 비해 학업이나
진로에 대한 고민이나 도전이 부족하다(Yim, Kim, \& Han, 2014; Choi \& Chung, 2012). 참여자들 또한 다른 학과 학생과의 교류가 부족했기 때문에 정보습득뿐만 아니 라 대인관계나 사회기술에 대한 부족함을 느끼게 되고, 이 로 인해 라이프스킬의 필요성을 실감하였다.

넷째, 참여자들은 PEAK 프로그램에 참여하면서 다양한 도움 요인과 방해 요인을 경험하였다. 학생선수들은 수동적 인 학교 생활로 인해 스스로 해야 하는 것에 대해 두려움을 느낀다(Park et al., 2016). 그리고 학교생활이 익숙하지 않 은 학생선수들에게는 학교 내의 공간이나 프로그램 이용, 자신보다 높은 위치의 상담 교사나 교수에 부담을 가질 수 있다(Song, Eom, \& Shin, 2010). 이와는 달리 연구참여자 들이 프로그램을 지속하는 데 도움이 되었던 사회적 지지 대 상은 프로그램 운영자였다. 그들은 자칫 선수들에게 권위적 으로 비추어질 수도 있었다. 하지만 조력자이자 선배로서 참여자들의 감정과 상황을 이해하려고 노력하였다.

운동선수에 대한 사회적 지지는 그들의 정서와 문제해결 능력에 영향을 미친다(Ahn \& Lee, 2015). 사회적 지지 정 도가 높을수록 엘리트 선수들이 진로를 탐색하고 방향을 모 색하는 데에도 긍정적인 영향을 줄 수 있다(Kim \& O, 2017; Kwon, 2017). 프로그램 내에서 느껴지는 운영자의 지속적인 관심과 지원, 그리고 동료들의 캐어링 분위기는 선수들이 프로그램에 지속적으로 참여할 수 있는 원동력이 되었다.

다섯째, 프로그램에 사용된 워크북은 참여자들의 라이프 스킬을 일상으로 전이시키는 데 핵심적인 도구가 되었다. 그간 국내·외 라이프스킬 연구에서는 라이프스킬 전이에 대 한 중요성과 전이를 위한 방법을 강조해 왔으나 구체적인 전 략까지는 제시되지 못했다. 이에 Pierce와 동료들(2017), Jacob과 Wright(2018)는 라이프스킬 전이 모델을 통해 라 이프스킬의 전이 과정과 효과적인 전이를 위한 필수 요소를 제안하였다.

선행 모델에서는 공통적으로 전이를 발생하고 촉진하기 위해서는 참여자의 경험과 지식을 연결할 수 있는 인지적 촉 매 과정이 필요함을 강조하였다. 이에 PEAK 프로그램에서 는 전이에 영향을 미치는 다양한 요소 중 핵심적인 촉매 기 제로 워크북을 활용하였다. 워크북은 참여자가 선수 경험을 통해 체득한 라이프스킬을 발견하고 이를 학업이나 일상생 활에 적용해 볼 수 있도록 구성되었다. 워크북을 통해 라이 프스킬을 일상에 적용해 보는 사례가 늘어가면서 전이가 발 
생되었다. 그리고 참여자들은 운동을 통해 라이프스킬이 자 신에게 잠재되어 있었다는 사실을 깨달았다. 그리고 이를 자각하고 활용하기 위해서는 의도적인 연습이 필요함을 이 해했다.

참여자들은 운동을 통해 인간관계에서 지켜야 할 기본적 인 행동예절을 이미 습득하고 있었다. 그러나 그동안 그것 이 자신의 라이프스킬임을 지각하지 못했기에 PEAK 프로 그램 참여는 운동과 일상생활의 연결점을 찾는 기회가 되었 다. 시합을 준비하기 위해 체중을 조절하고 몸 관리를 하는 방법 또한 일상생활에서 충분히 활용되는 기술임을 깨달았 다. 시합장에서의 규칙과 예의를 준수하는 모습은 시합장 밖에서도 충분히 자신의 강점으로 활용될 수 있었다. 참여 자들은 PEAK 프로그램을 통해 이러한 라이프스킬이 일상 이나 수업시간에도 똑같이 적용될 수 있음을 깨달았다. 선 수들의 이러한 경험은 $\operatorname{Lim}(2019)$ 의 연구와 유사하다. 그는 선수들이 스포츠에서 경험하는 훈련, 경쟁, 목표와 성취, 지 도자-선후배 관계 등 모든 상황이 라이프스킬로 발현될 수 있는 기반이 된다고 주장한 바 있다.

\section{결론 및 제언}

이 연구는 대학 태권도선수들의 PEAK 프로그램 참여 과 정을 근거이론을 통해 탐색하였다. 연구 결과 'PEAK 프로 그램 참여하기'가 중심현상으로 나타났고 인과적 상황은 '좋지 않은 수업태도'와 '무기력한 일상생활'로 나타났다. 맥락적 조건은 ‘수업 참여 필요성 인식' 과 ‘이중경력 필요성 인식', '프로그램 참여 동기'로 나타났고 중재적 조건은 '프 로그램 참여 방해 요인'과 '프로그램 참여 도움 요인'이었 다. 작용/상호작용 전략은 '캐어링 분위기'와 '전이 촉진' 이 었고 작용/상호작용 전략에 따라 '학습태도의 변화'와 '라이 프스킬의 변화'가 나타났다. 그리고 PEAK 프로그램 참여 과정에서 나타난 핵심범주는 "학습능력 향상과 라이프스킬 전이 가능성 확인" 이었다. 이 연구 결과를 토대로 후속연구 를 위한 제언을 하면 다음과 같다.

첫째, 국내 라이프스킬 프로그램 개발과 기존 프로그램 의 보완이 필요하다. 국외에서는 다양한 종목과 대상을 기 반으로 한 스포츠 라이프스킬 프로그램이 활성화되고 있으 나 국내에서는 프로그램 개발과 활용 사례가 적다. 이 연구 에서 사용된 PEAK 또한 국내 실정에 맞게 보완 및 현장 적

\section{용 사례가 축적되어야 한다.}

둘째, 라이프스킬 전이에 대한 합리적인 논의가 이어져 야 한다. 라이프스킬은 라이프스킬의 적용과 전이가 핵심 개념이다. 라이프스킬의 효과적인 현장 적용을 위해서는 라 이프스킬의 지각-습득(발달)-전이 과정을 입체화해야 한다. 하지만 전이를 위한 구체적인 전략과 방법에 대한 제시는 부 족하다. 이 연구에서는 질적 접근을 통해 프로그램 참여 과 정에 집중하여 전이 과정을 일부 탐색하였다. 그러나 자료 수집 기간과 시점의 제약으로 인해 전이 과정만을 집중적으 로 조명하지는 못하였다. 추후 연구에서는 라이프스킬의 전 이 촉진을 위한 구체적인 전략과 전이 과정의 심층적 탐색이 요구된다.

셋째, 라이프스킬 전이에 관한 논의는 개념적 모델 개발 로 이어질 수 있다. 모델 개발은 기존 스포츠심리학의 영역 을 확장한다. 가령 기존 스포츠 심리기술 연구는 선수들의 기능향상을 통한 최상수행에 관심을 둔다. 하지만 라이프스 킬과 전이는 이보다 거시적인 생태학적 관점에서 접근한다. 즉 스포츠 라이프스킬은 스포츠 환경 내에서 배운 가치를 삶 으로 적용하고 활용하는 것에 궁극적인 목표가 있다. 이 때 문에 개념적 모델이 무엇보다 중요하다. 따라서 해외 스포 츠심리학자들에 의해 시도된 라이프스킬 전이 모델을 고찰 하고 이에 대한 문화적 특성을 반영한 한국형 라이프스킬 전 이 모델을 개발할 필요가 있다.

넷째, 다양한 라이프스킬 코칭 매뉴얼 개발이 요구된다. 이 연구의 중심현상인 프로그램 참여를 유지 시킨 상호작용 전략은 바로 운영자의 사회적 지지와 캐어링 분위기였다. 양질의 라이프스킬 프로그램이라 하더라도 운영자가 어떠 한 철학을 가지고 지도하며 대상자에게 접근하느냐에 따라 상이 한 결과를 가져올 수 있다. 또한 코로나 19로 인해 비 대면 강의가 확산되고 있는 현실을 고려한 지도 매뉴얼이나 프로그램 운영 관련 연구 성과들이 보고되어야 한다.

다섯째, PEAK를 더 다양한 종목 대상자에게 적용할 필 요가 있다. PEAK가 개발된 직후 대학 태권도 선수를 대상 으로 적용하였다. 이 연구도 대학 태권도 선수만을 대상으 로 프로그램이 진행되었다. 따라서 후속연구는 여러 종목의 학생선수를 대상자로 할 필요가 있다.

여섯째, 연구방법의 다양성이 요구된다. 본 연구는 $\mathrm{PEAK}$ 프로그램 참여 초기, 참여 과정, 참여 결과의 맥락과 전반적인 과정을 파악하고자 근거이론을 활용하였다. 추후 연구에서는 이러한 현상과 실제 체험을 내부자적 시각에서 
접근하는 실행연구(action research)와 같은 다양한 질적 연구방법이 적용될 필요가 있다.

이 연구를 통해 국내 라이프스킬 프로그램에 대한 다각적 인 접근과 스포츠 라이프스킬 전이에 대한 구체적인 논의가 이어지기를 기대해본다.

\section{참고문헌}

Ahn, S. W., \& Lee, C. H. (2015). The Effect of Middle\&\#8228;High School Athletes' Social Support on Problem Solving Ability Journal of Learner-Centered Curriculum and Instruction, 15(12), 857-873.

Allen, G., \& Rhind, D. (2019). Taught not caught: exploring male adolescent experiences of explicitly transferring life skills from the sports hall into the classroom. Qualitative Research in Sport, Exercise and Health, 11(2), 188-200.

Bae, J. S., Lim, T. H., \& Jang, C. Y. (2019). Exploring the Life Skills Model for Taekwondo Education. Korean Journal of Sport Psychology, 31(1), 81-91.

Choi, H. Y. \& Chung, Y. C. (2012). The Narratives of Retired Female Handball Players. Korean Journal of Physical Education, 51(6), 83-93.

Corbin, J. M., \& Strauss, A. (1990). Grounded theory research: Procedures, canons, and evaluative criteria. Qualitative sociology, 13(1), 3-21.

Danish, S. J. (2002). SUPER(Sports United to Promote Education and Recreation)program leader manual (3rd ed.). Richmond, VA: Life Skills Center, Virginia Commonwealth University.

Danish, S. J., Forneris, T., \& Wallace, I. (2005). Sport-based life skills programming in the schools. Journal of Applied School Psychology, 21(2), 41-62.

Danish, S., Meyer, A., Mash, J., Howard, C., Curl, S., Brunelle, J., \& Owens, S. (1998). Going for the goal: Leader manual and student activity book. Richmond, VA: Life Skills Center.

Gould, D., \& Carson, S. (2008). Life skills development through sport: Current status and future directions. International review of sport and exercise psychology, 1(1), 58-78.
Hardcastle, S. J., Tye, M., Glassey, R., \& Hagger, M. S. (2015). Exploring the perceived effectiveness of a life skills development program for high-performance athletes. Psychology of Sport and Exercise, 16, 139-149.

Hodge, C. J., Kanters, M. A., Forneris, T., Bocarro, J. N., \& Sayre-McCord, R. (2017). A Family Thing: Positive Youth Development Outcomes of a Sport-Based Life Skills Program. Journal of Park \& Recreation Administration, 35(1), 34-50.

Holt, N. L., Neely, K. C., Slater, L. G., Camiré, M., Côté, J., Fraser-Thomas, J., ... \& Tamminen, K. A. (2017). A grounded theory of positive youth development through sport based on results from a qualitative meta-study. International review of sport and exercise psychology, 10(1), $1-49$.

Hong, N. M., Sin, M. H., Park, E. H., \& Park, J. H. (2013). The Experience of School Dropouts Who Return to Academy: Based on the Grounded Theory Methodology. Journal of Adolescent Welfare, 15(1), 121-153.

Hong, S. H. (2005). Theoretical Study on Retirement from Sport. Journal of Sport and Leisure Studies, 23, 101-110

Jacobs, J. M., \& Wright, P. M. (2018). Transfer of life skills in sport-based youth development programs: A conceptual framework bridging learning to application. Quest, 70(1), 81-99.

Jang, C. Y., Lim, T. H., Bae, J. S., Jung, H. W., \& Kim, Y. H. (2020). Development and Validation of the Life Skills Scale for Student-Athletes. Korean Journal of Sport Psychology, 31(2), 27-41.

Kang, S. W. (2015). A Study on Differences of Career Barriers, Employment Stress, and Career Development Behavior among Collegiate athletes, Sport-majored College Students, and Non-sport-majored College Students. Korean Journal of Physical Education, 54(1), 83-95.

Kendellen, K., \& Camiré, M. (2019). Applying in life the skills learned in sport: A grounded theory. Psychology of Sport and Exercise, 40, 23-32.

Kim, D. H. (2011). The process of adjustment to the school Lives from a normal student to a student athlete. Korean Journal of Sport Pedagogy. 18(1), 71-90.

Kim, D. H. (2012). What does the Sport Mean to Me?: 
Narrative Inquiry about the Meaning of the Life of a Korean Sport Player. Korean Journal of Sport Science, 23(2), 343-359.

Kim, D. H. (2015). A grounded theory approach toward the nonnalization process in amateur sports referee. Korean Journal of Physical Education, 54(3), 253-264.

Kim, D. W., Kim, S. Y., \& Kim, D. H. (2014). A Narrative Inquiry on the University Experiences of Student-Athletes to Study. Korean Journal of Physical Education, 53(3), 329-340.

Kim, E. J., Lee, K. M., \& Jang, S. H. (2015). 'Female Basketball Athletes Entered the College of Education': A Storyabout Education and Career of Student Athletes. The Korean Journal of Physical Education, 54(4), 139-155.

Kim, G. J. \& O, Y. P. (2017). A Study on Career Exploration Behavior of Elite Taekwondo Player. Korean Journal of Physical Education, 56(1), 661-682.

Kim, M. J. \& Chung, H. J. (2012). Their Own Learning: Ethnography for The Learning of Athlete-Students. Korean Journal of Physical Education, 51(2), 51-62.

Kwon, O. J. (2017). Exploring the life skills of drop-out elite athletes. Korean Journal of Sport Science, 28(3), 724-738.

Kwon, O. J., Lim, T. H., \& O’Sullivan, D. M. (2020). Evaluation of Life Skills Program to Change Learning Attitudes of Former Student-Athletes. Psychology and Education, 57(4), 226-232.

Lee, O. S. (2016). Understanding Implementation of an Afterschool Life Skill Development Program in Two Elementary Schools. Journal of Korean Physical Education Association for Girls and Women, 30(4), 231-253.

Lee, Y. C. (2014). Reflecting on the Grounds for Grounded Theory: Methodology and Methods. Korean Policy Sciences Review, 18(1), 187-214.

Lim, T. H. \& Jang, C. Y. (2017). The application and its effect of life skills program in sport. Korean Journal of Sport Science, 28(3), 577-591.

Lim, T. H. (2019). Changes in Life Skills and Learning Attitudes of Student Athletes by Applying PEAK Program. Korean Journal of Sport Psychology, 30(2), 15-28.

Lim, T. H., Bae, J. S., \& Jang, C. Y. (2019). The Validation of Korean Life Skills Transfer Survey (KLSTS). Korean Journal of Sport Psychology, 29(4), 1-12.
Lim, T. H., Kwon, O. J., Yang, Y. K., Yun, M. S., \& Bae, J. S. (2019). Validation of the Korean Life Skills Scale for Sport (KLSSS). Korean Journal of Sport Science, 30(1), 20-33.

Lim, T. H., Yang, J. Y., Bae, J. S., \& Yun, M. S. (2019). Verifying the worksheets for improving life skills and resilience of collegiate Taekwondo athletes. Korean Journal of Sport Science, 30(4), 700-719.

NHL [Website]. (2020, December 3). Hockey Is For Everyone. Retrieved from https://www.nhl.com/community/hockey-is -for-everyone

Park, K. H., Won, Y. S., \& Cho, E. Y. (2016). The Analysis on the Career Transition of Early Retired Baseball Student-athletes by Grounded Theory. Korean Journal of Physical Education, 55(1), 509-520.

Park, S. H. \& Shin, S. Y. (2017). Grounded Theoric Approach about Formation Process of Social Networks among Student Athletes who Dropped Out in University. Korean Journal of Physical Education, 56(6), 95-115.

Petitpas, A. J., Van Raalte, J. L., Cornelius, A. E., \& Presbrey, J. (2004). A life skills development program for high school student-athletes. Journal of primary prevention, 24(3), 325-334.

Pierce, S., Erickson, K., \& Dinu, R. (2019). Teacher-coaches' perceptions of life skills transfer from high school sport to the classroom. Journal of Applied Sport Psychology, 31(4), 451-473.

Pierce, S., Gould, D., \& Camiré, M. (2017). Definition and model of life skills transfer. International Review of Sport and Exercise Psychology, 10(1), 186-211.

Shim, Y, S. (2012). Validation of the Korean Version of Perceived Caring Climate Scale and Its Influence on Elementary School Students' Attitudes toward Physical Education Class. The Korean Journal of Elementary Physical Education, 18(3), 133-142.

Shin, G. L. \& Kim, M. Y. (2003). Using grounded theory in nursing. Seoul: Hyunmunsa.

Song, Y. G., Eom, H. J., \& Shin, M. J. (2010). Understanding for Learning experiences on athlete students': with an emphasis on the right to Learn. Korean Journal of Sport Pedagogy 17(1), 89-109

Strauss, A., \& Corbin, J. (1998). Basics of qualitative research 
techniques. Thousand Oaks, CA: Sage publications.

Weiss, M. R. (2006). The First Tee 2005 research summary: longitudinal effects of the First Tee Life Skills Educational Program on positive youth development. St. Augustine, FL: The First Tee.

Williams, C., Neil, R., Cropley, B., Woodman, T., \& Roberts, R. (2020). A systematic review of sport-based life skills programs for young people: The quality of design and evaluation methods. Journal of Applied Sport Psychology, $1-27$.
Yim, Y. S., Kim, J. S., \& Han, M. S. (2014). The Meaning of Study through Drop-out Student-Athletes' Experience. Journal of Sport and Leisure Studies, 57, 91-104.

Yu, K. W., Jung, J. W., Kim, Y. S., \& Kim, H. B. (2018). Understanding Qualitative Research Methods. Seoul: Parkyoungsa

Yu, T. H. \& Yi, J. W. (2004). Schooling and the culture of school athletics. Korean Journal of Physical Education, 43(4), 271-282.

\title{
근거이론을 통해 본 대학 태권도선수들의 PEAK 프로그램 참여 과정
}

\author{
임태희 ${ }^{1}$, 권오정 ${ }^{2}$, 윤미선 $^{3}$, 배준수 $^{3}$, 양윤경 ${ }^{4}$ \\ ${ }^{1}$ 용인대학교 교수 \\ 2건국대학교 미래지식교육원 시간강사 \\ ${ }^{3}$ 용인대학교 박사과정 \\ 4강남대학교 박사과정
}

[목적] 이 연구는 근거이론을 통해 대학 태권도선수들의 PEAK 프로그램 참여 과정을 탐색하는 데 목적이 있었다. [방법] 대한태권도협회에 선수로 등록된 Y대학교의 학생선수 12 명을 대상으로 심층면담을 진행하였 다. 수집된 자료는 근거이론의 개방코딩, 축코딩, 선택코딩을 활용해 분석하였고 추출된 개념들의 패러다임 모형을 완성하고 이야기 윤곽을 통해 핵심범주를 추출하였다. [결과] 'PEAK 프로그램 참여하기'가 중심현상으 로 나타났다. 인과적 상황은 ‘좋지 않은 수업태도'와 '무기력한 일상생활’로 나타났다. 맥락적 조건은 ‘수업 참 여 및 이중경력 필요성 인식'과 '프로그램 참여 동기'로 나타났다. 중재적 조건은 '프로그램 참여 방해 요인'과 '프로그램 참여 도움 요인'이었다. 작용/상호작용 전략은 '캐어링 분위기'와 '전이 촉진' 이었다. 결과는 ‘학습 태도의 변화'와 '라이프스킬의 변화'가 나타났다. [결론] 참여자들은 PEAK 프로그램을 통해 학습태도가 향상 되었고 라이프스킬의 전이 가능성을 확인하였다. 이 연구를 통해 국내 라이프스킬 및 전이에 대한 다양한 연구 와 구체적인 논의가 이어지기를 기대한다.

주요어: 라이프스킬, 학습태도, 긍정적 발달, 명시적 접근 